\title{
(2) OPEN ACCESS \\ Interface leakage during neonatal CPAP treatment: a randomised, cross-over trial
}

\author{
Markus Falk (1) 1,2 Kolbrun Gunnarsdottir, 1,3 Sonja Baldursdottir, ${ }_{1}^{1,3}$ \\ Snorri Donaldsson, 1,3 Baldvin Jonsson, ${ }^{1,3}$ Thomas Drevhammar (1) 1,2
}

\begin{abstract}
- Additional supplemental material is published online only. To view, please visit the journal online (http://dx.doi. org/10.1136/archdischild2021-321579)
\end{abstract}

${ }^{1}$ Department of Women's and Children's Health, Karolinska Institutet, Stockholm, Sweden ${ }^{2}$ Department of Anesthesiology, Östersunds sjukhus, Östersund, Sweden

${ }^{3}$ Department of Neonatology, Karolinska Universitetssjukhuset, Stockholm, Sweden

\section{Correspondence to}

Dr Markus Falk, Department of Women's and Children's Health, Karolinska Institutet, 17177

Solna, Sweden;

markus.falk@ki.se

Received 7 January 2021

Revised 14 April 2021

Accepted 20 April 2021
Check for updates

(C) Author(s) (or their employer(s)) 2021. Re-use permitted under CC BY-NC. No commercial re-use. See rights and permissions. Published by BMJ.

\section{To cite: Falk $M$,}

Gunnarsdottir K, Baldursdottir $\mathrm{S}$, et al. Arch Dis Child Fetal Neonatal Ed Epub ahead of print: [please include Day

Month Year]. doi:10.1136/

archdischild-2021-321579

\section{ABSTRACT \\ Objective To determine leakage for two neonatal}

continuous positive airway pressure (CPAP) interfaces and evaluate leak-corrective manoeuvres.

Design The ToNIL (Trial of NCPAP Interface Leakage) study was a randomised, clinical, cross-over trial with data collection between August 2018 and October 2019. The primary outcome was blinded to the treating staff. Setting One secondary, 8-bed neonatal intensive care unit (NICU) and three larger (>15 beds), academic NICU referral centres.

Patients Newborn infants with CPAP were screened $(n=73)$, and those with stable spontaneous breathing, low oxygen requirement, postmenstrual age (PMA) over 28 weeks and no comorbidities were eligible. In total, 50 infants were included (median PMA 33 completed weeks).

Interventions Leakage was measured for both prongs and nasal mask, before and after leak-corrective manoeuvres. Interface application was performed in a randomised order by a nurse, blinded to the measured leakage.

Main outcome measures 30 s average leakage, measured in litres per minute (LPM).

Results Analyses showed a significantly lower leakage (mean difference $0.86 \mathrm{LPM}, 95 \% \mathrm{Cl} 0.07$ to 1.65 ) with prongs (median 2.01 LPM, IQR 1.00-2.80) than nasal mask (median 2.45 LPM, IQR 0.99-5.11). Leakcorrective manoeuvres reduced leakage significantly for both prongs (median 1.22 LPM, IQR 0.54-1.87) and nasal mask (median 2.35 LPM, IQR 0.76-4.75).

Conclusions Large leakages were common for both interfaces, less with prongs. Simple care manoeuvres reduced leakage for both interfaces. This is the first report of absolute leakage for nasal interfaces and should encourage further studies on leakage during CPAP treatment.

\section{INTRODUCTION}

The beneficial effects of continuous positive airway pressure (CPAP) for newborns in respiratory distress have been thoroughly confirmed ${ }^{1}$ since its clinical introduction. $^{2}$ CPAP with short nasal prongs or nasal mask is currently the recommended first-line treatment for neonates in respiratory distress. ${ }^{3}$

Several randomised trials have compared mask and prong interfaces using CPAP failure and nasal injuries as primary outcomes. Three recent systematic reviews favour nasal masks for both of these outcomes. $^{4-6}$ The heterogenicity of the included studies, and the different CPAP interfaces used, was recognised in all reviews. Nasal trauma has been

\section{What is already known on this topic?}

- Comparing studies favour nasal mask over prongs when looking at nasal injuries and continuous positive airway pressure (CPAP) failure.

- During neonatal CPAP treatment, interface leakages diminish the propagated pressure and possibly reduce the beneficial CPAP effect.

- Measuring leakages during neonatal CPAP treatment is challenging, and no studies on absolute leakage exist.

\section{What this study adds?}

The flow-through method can accurately measure absolute leakage without adding dead space or work of breathing.

- When comparing absolute leakage during neonatal CPAP treatment, prongs leak significantly less than nasal mask.

- When guided by the measured leakage, simple care manoeuvres can reduce interface leakage in the vast majority of patients with both nasal mask and prongs.

described with both interfaces, most commonly at the philtrum or glabella with nasal mask and at the septum with prongs. The rotational use of prongs or nasal mask to minimise trauma ${ }^{78}$ has not shown to reduce injuries. ${ }^{9}$

The reason for CPAP failure reduction with nasal masks is not fully understood. Suggested explanations were that masks have less resistance and provide more stable CPAP. ${ }^{10}{ }^{11}$ An increased resistance, together with a leakage, leads to a reduction in pharyngeal pressure ${ }^{12}$ which was another suggested explanation by Kieran et al. ${ }^{7}$ To achieve an efficient delivery of CPAP, a tight fit without leakage has been assumed to be of importance. This might increase the risk of nasal trauma, a conflict well recognised. ${ }^{51012}$ The link between leakage and interface type, design and other factors has not been well studied.

The suggested method for reporting leakage by the European Respiratory Society/American Thoracic Society task force is a ratio between expiratory and inspiratory volumes. ${ }^{13}$ Previous CPAP studies reported that high levels of leakage were incompatible with determining tidal volumes and 
breathing patterns and resulted in high exclusion rates. In 2009, Schmalisch $e t a l^{14}$ suggested that a solution would be to report leakage flow rather than tidal volume ratios.

Our Trial of NCPAP Interface Leakage (ToNIL) used improved methods allowing measurements of high leakage levels and was a randomised, clinical, two-period cross-over study on leakage during CPAP with nasal prongs and nasal mask. Our primary aim was to compare absolute leakage for prongs and nasal mask. Our secondary aim was to evaluate if leakage could be reduced by common care manoeuvres.

\section{METHODS}

\section{Study design}

The cross-over design was chosen to use each patient as its own control thereby reducing the number of infants needed for the study. The risk for carry-over effects was considered negligible.

\section{Study population}

Patients were included between August 2018 and October 2019 at four Swedish sites: an 8-bed neonatal intensive care unit at the Östersund hospital and three larger (>15 beds) tertiary referral centres at the Karolinska University Hospital, Stockholm.

Whenever investigators were available, newborn infants with CPAP were screened for eligibility. Infants older than 28 weeks of postmenstrual age (PMA) with stable spontaneous breathing were included after informed parental consent. Exclusion criteria were cardiac or respiratory malformations, facial defects or injuries, $\mathrm{FiO}_{2}>0.5$, circulatory instability, recent surgery or recently extubated.

The starting interface was randomised using sequentially numbered, sealed envelopes, opened when the system was calibrated for measuring. The envelopes were prepared by a researcher with no connection to the study, and the $1: 1$ sequence was generated by sealedenvelope.com, stratified on age $(<34$ weeks or $\geq 34$ weeks) and presence of nasogastric tube using permuted blocks of variable sizes.

The study was ethically approved, conducted according to good clinical practice (GCP) standards and registered at the US National Institutes of Health (ClinicalTrials.gov \#NCT03586856). No changes to the study design, eligibility criteria or trial outcomes were made after commencement.

\section{Study interventions}

A schematic equipment setup figure is provided as online supplemental figure 1 . The ordinary flow generator was replaced with an oxygen mixer and a rotameter to avoid problems with leakage compensation. The fresh gas was humidified using a MR850 humidifier (Fisher \& Paykel, Auckland, New Zealand) and connected to systems with the original Infant Flow design (nFlow, Intersurgical, Berkshire, UK or Inspire nCPAP, Inspiration Healthcare, Leicester, UK). Both manufacturers provided prongs and nasal masks with similar design and size range.

Two custom SFM-3200-60-AW flow meters (Sensirion AG, Staefa, Switzerland) were added to the patient circuit enabling flow-through measurements; one on the fresh-gas supply and the second on the patient expiratory limb. No dead space and minimal resistance was added. ${ }^{15} 16$ The flow meters were calibrated with the correct oxygen level and conditioned gas, using a Defender 510 flow meter (Mesalabs, NJ, USA). A calibrated Honeywell pressure sensor (40PC001B1A; Honeywell, Freeport, IL, USA) was used to set the prescribed CPAP. For each interface, connectors were checked for leakage and the flow meters zeroed against each other. Flow and pressure data were collected at $500 \mathrm{~Hz}$ using single-board microcontrollers (Arduino Uno, Arduino, Italy) and a data acquisition device (NI-6451; National Instruments, Austin, TX, USA). Recordings were labelled, stored and processed using customised software (LabVIEW 2015; National Instruments).

For each study, data were collected with the infant in an incubator, cot or during skin-to-skin care and at least $30 \mathrm{~min}$ after feeding (if not continuous). Parents were invited to be present and comfort the infant. A nurse applied the randomised first interface with a size of her or his choice, blinded to leakage measurements at all times.

Flow and pressure was recorded for $30 \mathrm{~s}$ after securing the interface and the infant was breathing quietly. If the measured leakage exceeded 0.2 LPM, the nurse was asked to leave before corrective manoeuvres were attempted by the investigators, guided by the measured leakage. Not all manoeuvres were tested on each infant and selection was based on previous attempts and experience. Each manoeuvre was evaluated with a 30 s recording until leakage was below 0.2 LPM or no further reduction was possible. The same procedure was then repeated with the second interface. No wash-out period was included as no carry-over effects were expected.

\section{Sample size and statistical analyses}

No sample size calculations were possible as absolute leakage during neonatal CPAP treatment has not been previously measured and published. A study sample size of 50 infants was chosen, based on the sizes of previous, experimental neonatal CPAP cross-over trials.

Data were imported to SPSS V.26 and analyses were both parametric (independent samples and paired samples t-test) and non-parametric (Wilcoxon signed-rank test and Mann-Whitney $\mathrm{U})$.

In the regression analyses, PMA was removed due to co-linearity with weight and the stratification on nasogastric tube was removed due to a highly asymmetrical distribution. Univariable linear regression analyses were performed on leakage for each interface against the remaining strata, weight and CPAP level. A $\mathrm{p}$ value below 0.05 was considered statistically significant.

\section{RESULTS}

Seventy-three infants were screened for eligibility and 52 were enrolled after consent (figure 1). Due to equipment problems, two infants were never measured. One was never randomised, and one was randomised but not measured. All analyses included the remaining 50 study participants, equally randomised to start with either patient interface (table 1).

Measurements were well tolerated with no adverse events or need to increase the oxygen inspiratory fraction during the study. For each infant, the median time connected to the measuring equipment was $25 \mathrm{~min}$ (IQR 21-30). Analyses showed no significant carry-over or period effect (not reported).

There was a significantly lower leakage (mean difference 0.86 LPM, 95\% CI 0.07 to $1.65, \mathrm{p}=0.034$ ) with nasal prongs (median 2.01 LPM, IQR 1.00-2.80) than nasal mask (median 2.45 LPM, IQR 0.99-5.11). Leakages ranged from none to 9.9 litres per minute (LPM). A leakage above $0.2 \mathrm{LPM}$ was present with at least one interface in all patients (figure 2). Regression analyses showed that leakage was associated to the set CPAP level for both prongs ( $\beta 0.78,95 \% \mathrm{CI} 0.15$ to $1.41, \mathrm{p}=0.02)$ and nasal mask ( $\beta 1.17,95 \%$ CI 0.13 to $2.20, p=0.03)$, but was not significantly associated to the PMA stratification or weight. 


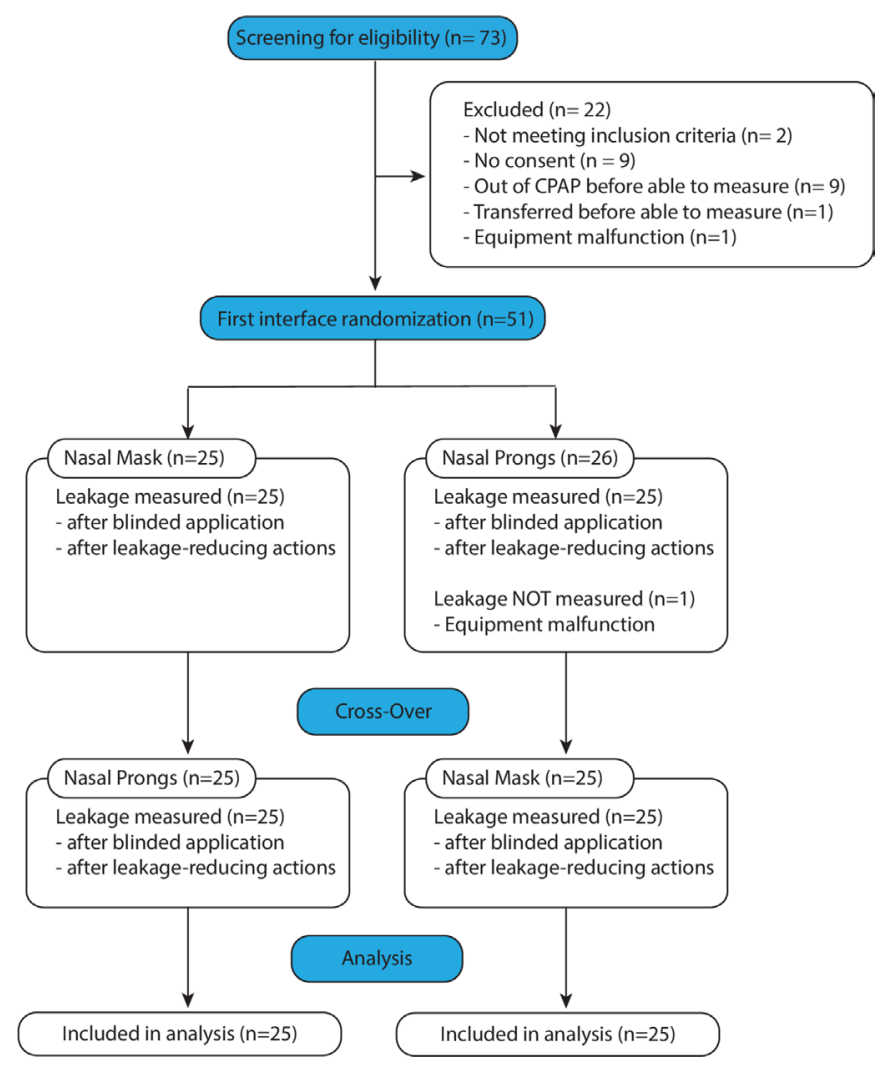

Figure 1 The CONSORT Flow Diagram

With an initial leakage above 0.2 LPM, attempted non-blinded leak-corrective manoeuvres were successful in $96 \%$ of the cases with prongs (45/47) and 98\% with nasal mask (48/49). The median reduction in leakage was 1.22 LPM (IQR 0.54-1.87) for prongs and 2.35 LPM (IQR 0.76-4.75) for nasal mask, both statistically significant $(\mathrm{p}<0.001)$ (figure 3$)$.

\section{DISCUSSION}

As far as we know, this is the first study that reports absolute CPAP interface leakage measured in litres per minute. We found that after applying a CPAP interface (prongs or mask) in a randomised order, followed by a cross-over, less leakage was seen with prongs compared with nasal mask. The amount of leakage could be reduced by simple care manoeuvres for both interfaces when guided by the measured leakage. For each patient, leakage was rarely the same for both interfaces (dashed line figure 2) which indicates that leakage was related to the type of interface.

Our results confirm that interface leakages are common, often high and consistent with the high exclusion rates due to leakages reported in previous studies: Hückstädt $e t a l^{17}$ excluded 49 of 69 patients with an excessive leakage $(1.3$ to $2.0 \mathrm{~L} / \mathrm{min}$ ) and Fischer et $a l^{18}$ reported that 31 of 32 infants displayed leakages exceeding what was possible to measure $(>1.4 \mathrm{~L} / \mathrm{min})$. Our median leakage was higher than their equipment limits and could explain their high exclusion rates.

Leakage is a suggested factor that may affect CPAP quality and clinical outcome. Other potentially important factors are CPAP level, imposed work of breathing and pressure oscillations present in bubble CPAP systems. Little is known about how these factors interact and their role in optimising CPAP treatment.

Recent meta-analyses on clinical outcome measures, such as CPAP failure, have indicated that nasal mask is more favourable compared with nasal prongs, ${ }^{4-6}$ but the reasons have not yet
Table 1 Participant demographics and clinical characteristics

\begin{tabular}{|c|c|c|c|}
\hline & $\begin{array}{l}\text { Nasal prongs first } \\
\mathrm{n}=25\end{array}$ & $\begin{array}{l}\text { Nasal mask first } \\
n=25\end{array}$ & $\begin{array}{l}\text { Total } \\
n=50\end{array}$ \\
\hline \multicolumn{4}{|c|}{$\begin{array}{l}\text { PMA at study (completed } \\
\text { weeks) }\end{array}$} \\
\hline Median (IQR) & $33(31-38)$ & $33(32-38)$ & $33(32-38)$ \\
\hline Range & 29-41 & $28-42$ & $28-42$ \\
\hline \multicolumn{4}{|c|}{ PNA at study (days) } \\
\hline Median (IQR) & $1(0-3.5)$ & $1(0.5-4.5)$ & $1(0-4)$ \\
\hline Range & $0-52$ & $0-74$ & $0-74$ \\
\hline \multicolumn{4}{|l|}{ Weight (g) } \\
\hline Median (IQR) & 2012 (1496-3708) & $1844(1551-3202)$ & $1948(1517-3442)$ \\
\hline \multicolumn{4}{|l|}{ Gender, n (\%) } \\
\hline Female & $8(32)$ & $13(52)$ & $21(42)$ \\
\hline Male & $17(68)$ & $12(48)$ & $29(58)$ \\
\hline \multicolumn{4}{|c|}{ Delivery method, n (\%) } \\
\hline C-section & $14(56)$ & $12(48)$ & $26(52)$ \\
\hline Vaginal & $11(44)$ & $13(52)$ & $24(48)$ \\
\hline \multicolumn{4}{|c|}{ CPAP level $\left(\mathrm{cm} \mathrm{H}_{2} \mathrm{O}\right)$} \\
\hline Median (IQR) & $4.0(4-4)$ & $4.0(4-5)$ & $4.0(4-4)$ \\
\hline Range & $3-5$ & $2-6$ & $2-6$ \\
\hline \multicolumn{4}{|l|}{$\mathrm{SpO}_{2}(\%)$} \\
\hline Mean (SD) & $98(4)$ & 97 (3) & $97(3)$ \\
\hline \multicolumn{4}{|l|}{$\mathrm{FiO}_{2}(\%)$} \\
\hline Median (IQR) & $21(21-21)$ & $21(21-22.5)$ & $21(21-21.3)$ \\
\hline \multicolumn{4}{|c|}{$\begin{array}{l}\text { Previous surfactant treatment, } \\
\mathrm{n}(\%)\end{array}$} \\
\hline Yes & $2(8)$ & $7(28)$ & $9(18)$ \\
\hline No & $23(92)$ & $18(72)$ & $41(82)$ \\
\hline \multicolumn{4}{|c|}{$\begin{array}{l}\text { Previous mechanical ventilation, } \\
\mathrm{n}(\%)\end{array}$} \\
\hline Yes & $1(4)$ & $3(12)$ & $4(8)$ \\
\hline No & $24(96)$ & $22(88)$ & $46(92)$ \\
\hline \multicolumn{4}{|l|}{ CPAP duration (h) } \\
\hline Median (IQR) & $18.0(8.5-78)$ & $48.0(12.5-132)$ & $31.0(9.8-96.8)$ \\
\hline \multicolumn{4}{|c|}{ PMA at study, n (\%) } \\
\hline$<34$ weeks & $13(52)$ & $14(56)$ & $27(54)$ \\
\hline$\geq 34$ weeks & $12(48)$ & $11(44)$ & $23(46)$ \\
\hline \multicolumn{4}{|c|}{ Nasogastric tube, $n(\%)$} \\
\hline Yes & $24(96)$ & 24 (96) & $48(96)$ \\
\hline No & $1(4)$ & $1(4)$ & 2 (4) \\
\hline
\end{tabular}

PMA, postmenstrual age; PNA, postnatal age.

been fully explained. Our study measured leakage over a short period of time in stable infants with a minimal risk of failure. Relating our findings to results in previous clinicals trials with CPAP failure as an outcome is difficult. If there is a link between leakage and clinical outcome, it could be indirect through reductions in delivered pressure, pressure stability, imposed work of breathing or related to leakage compensation when using more complex CPAP drivers. This is speculative since leakage flow has, as far as we know, not been measured in any trials with clinical outcomes.

\section{Leak-corrective manoeuvres}

Leakage location cannot be determined from our measurements but can occur at the patient interface, through the mouth or to the stomach. Reducing leakage with simple manoeuvres was possible in most infants (figure 4). Even if it was easy to reduce leakage, we considered it not possible to go through a full list of standardised adjustments and compare their relative effectiveness.

The most successful leak-corrective manoeuvre was adjusting the seal of the interface and was achieved by adjusting the angle, straps, bonnet or manually changing the shape of the interface 


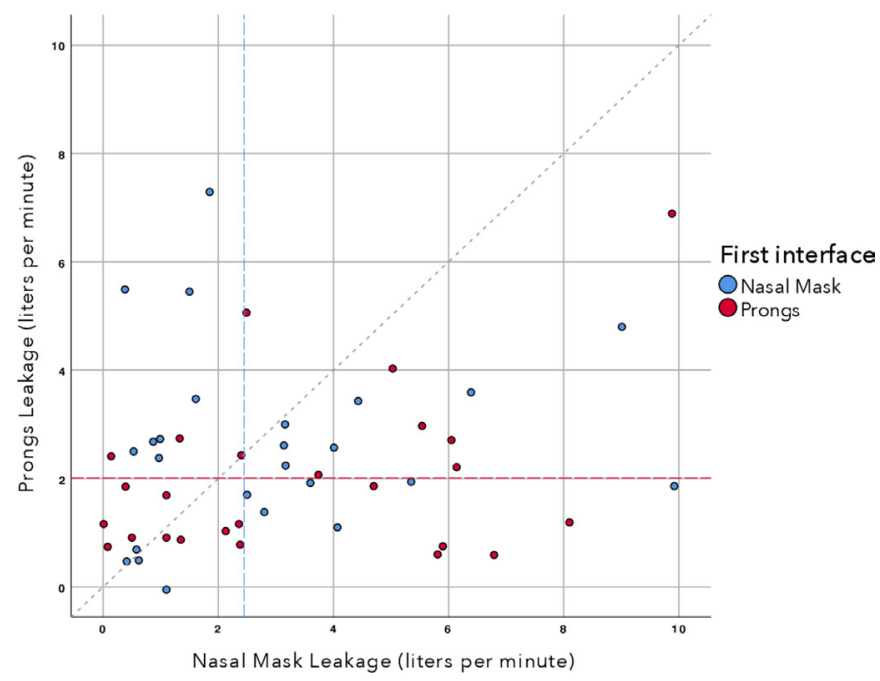

Figure 2 Absolute leakage for each patient and both interfaces. Each dot represents one patient. The absolute leakage in liters per minute for prongs is plotted on the $\mathrm{Y}$-axis and for nasal mask on the $\mathrm{X}$-axis. The dot color indicates the randomised starting interface. The colored dashed lines indicate median values and the grey dashed line indicates an equal leakage between interfaces, regardless of magnitude. For dots below the dashed line, absolute leakage is lower with prongs, and for dots above the line, absolute leakage is lower with nasal mask.

by external compression. In our infants with a nasal 4 Fr nasogastric tube, applying a gentle pressure at its interface entry was the second most successful manoeuvre for both interfaces. Placing the feeding line nasally might be an important cause of leakage. An oral placement might reduce leakage but was not tested in our trial. Larger feeding lines will likely increase leakage and interface design revisions to allow for a better seal around the feeding line entry are desirable.

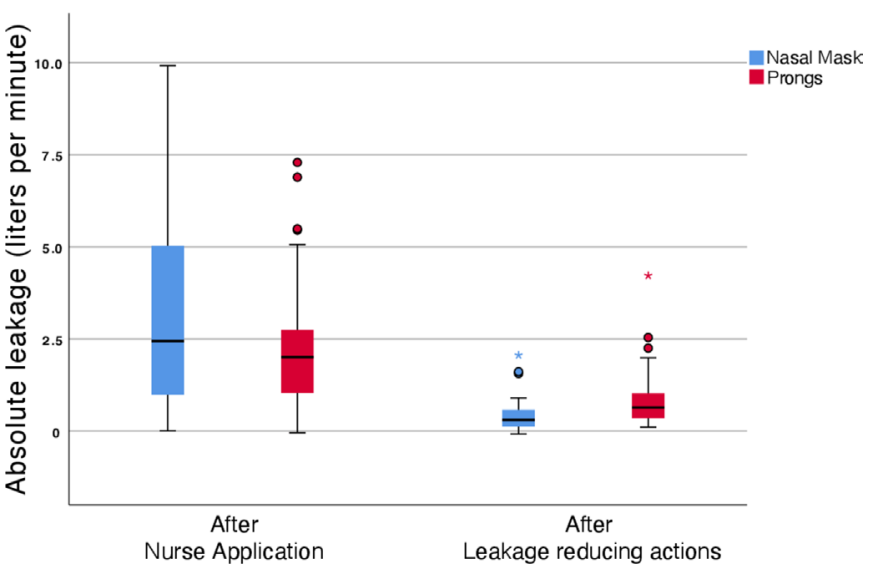

Figure 3 Boxplots on absolute leakage for each interface, directly after nurse application (blinded) and after leak-corrective maneuvers by the investigators (non-blinded). The absolute leakage directly after nurse application was significantly lower with prongs than nasal mask. Maneuvers to reduce leakage were guided by the absolute leakage presented on a screen and the reduction was significant for both interfaces. Bold line - median value, box - inter quartile range (IQR), lower whisker - minimum value, upper whisker - maximum value or 1.5 times IQR above median, circles - mild outliers (> 1.5 times IQR from median), asterisk - extreme outlier (> 3 times IQR from median). Negative values are artifacts due to flow meter error tolerances and arise when calibrating flow meters against each other.

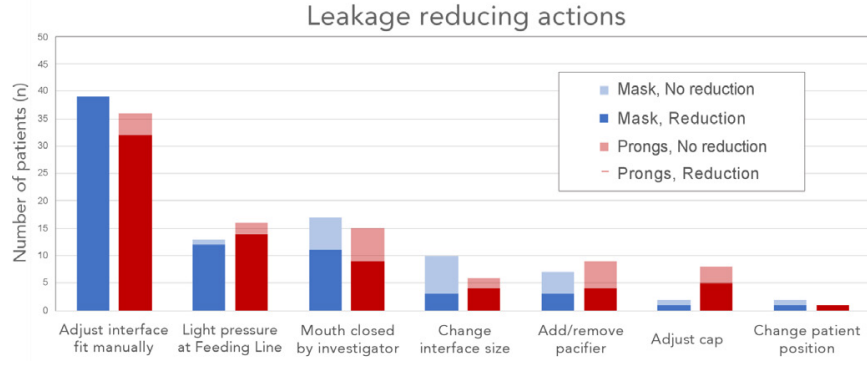

Figure 4 Manoeuvres attempted to reduce leakage in infants with a leakage above $0.2 \mathrm{~L} / \mathrm{min}$. The investigators were guided by the current leakage, displayed on a screen. Leakage reduction was possible in most infants, but no single manoeuvre was successful in all tested infants. The bar height represents all attempts ( 47 for prongs and 49 for nasal mask) and the lighter color represents failed attempts (no reduction). Several manoeuvres could be attempted in a single infant and were not performed in a standardised order.

Manual mouth closure during measurements and adding or removing pacifiers was tested in some, but not all, infants. Mouth closure was the third most successful manoeuvre. Early studies stated that neonates are obligate nose breathers, ${ }^{19}$ but later results show that neonates are able to breathe orally ${ }^{20}$ but prefer to breathe through the nose. ${ }^{21}$ The effect of oral breathing on CPAP treatment and leakage is not known. In a calm infant with closed mouth, inserting a pacifier was not feasible. No definitive conclusions can be drawn from the data on pacifier addition or removal.

In our setting, care was based on the advice that prongs should fill the nares comfortably and a mask with a snug fit was preferred. In the majority of patients, the most appropriate interface size was already selected which explains the low number of attempts with changing interface sizes. When attempted, leakage reduction by interface size change was more successful with prongs than mask.

Evaluating CPAP leakage in clinical practice includes listening to the sound the device makes, looking at the compensatory increase in driver flow and evaluating the clinical effect over time. These techniques are subjective, time consuming and seem outdated in modern intensive care of newborn infants. New tools for measuring and controlling leakage could be of great value, possibly contributing to less CPAP failure, minimising the need for mechanical ventilation and subsequently lead to less chronic lung disease.

\section{Limitations}

All infants were treated with the original Infant Flow device design. The results would likely be different if other types of CPAP devices or interfaces were used.

The time on each interface was short and leakage over time or during feeding and care was not investigated. Conclusions on long-term leakages cannot be made. The current method did not allow for identification of leakages split on exhalation and inhalation. Theoretically, a pressure-unstable system carries an increased risk for leakages during exhalation.

The second part of the study, exploring ways to reduce leakage, was not randomised and not all infants underwent the same interventions. This limits the possibility to draw any conclusions about the relative effect of each intervention but shows that a reduction was possible in most infants. The second part of the study should be considered hypothesis generating. 


\section{Future directions}

Our study method could be useful for researchers and possibly also for clinical use. We suggest that leakage should be considered a variable affecting treatment outcome and, together with interface type, resistance to breathing and CPAP level, could add information in both animal and human research trials.

Leakage monitoring during non-invasive support might also allow optimisation of nebulised drugs, including surfactant, as high levels of leakage will likely lead to the dilution of aerosols. Our findings suggest that a better fit, especially together with a nasogastric tube, might reduce leakage. If a reduced leakage improves the clinical outcome remains an open question.

Future studies should address the two major limitations of our trial: short registration time and measurements on stable infants only. To be clinically meaningful, leakage needs to be studied over longer periods, in unstable infants and linked to delivered CPAP and clinical outcome.

\section{CONCLUSION}

This is the first report on absolute leakage for CPAP interfaces. In our randomised, short-duration, clinical cross-over trial, nasal prongs had less leakage than nasal mask. High levels of leakage were common for both interfaces. When guided by measured leakage, simple manoeuvres could reduce leakage. The findings encourage studies on interface design and clinical effects of optimising leakage.

\section{Acknowledgements Statistical support provided by Anna Lindam and Robert} Lundqvist.

Contributors MF, TD: study design, equipment development, data collection, data and statistical analysis and manuscript writing. KG, SB, SD: study design, data collection, manuscript writing and review. BJ: study design, data interpretation, manuscript writing and review.

\section{Competing interests None declared.}

Patient consent for publication Not required.

Provenance and peer review Not commissioned; externally peer reviewed.

Data availability statement Data are available on reasonable request. Deidentified participant data and full trial protocol available from corresponding author to researchers who provide a methodologically sound proposal. Reuse of data permitted to achieve aims in the approved proposal.

Supplemental material This content has been supplied by the author(s). It has not been vetted by BMJ Publishing Group Limited (BMJ) and may not have been peer-reviewed. Any opinions or recommendations discussed are solely those of the author(s) and are not endorsed by BMJ. BMJ disclaims all liability and responsibility arising from any reliance placed on the content. Where the content includes any translated material, BMJ does not warrant the accuracy and reliability of the translations (including but not limited to local regulations, clinical guidelines, terminology, drug names and drug dosages), and is not responsible for any error and/or omissions arising from translation and adaptation or otherwise.

Open access This is an open access article distributed in accordance with the Creative Commons Attribution Non Commercial (CC BY-NC 4.0) license, which permits others to distribute, remix, adapt, build upon this work non-commercially, and license their derivative works on different terms, provided the original work is properly cited, appropriate credit is given, any changes made indicated, and the use is non-commercial. See: http://creativecommons.org/licenses/by-nc/4.0/.

ORCID iDs

Markus Falk http://orcid.org/0000-0002-4318-5039
Thomas Drevhammar http://orcid.org/0000-0002-4038-2221

\section{REFERENCES}

1 Gupta S, Donn SM. Continuous positive airway pressure: physiology and comparison of devices. Semin Fetal Neonatal Med 2016;21:204-11.

2 Gregory GA, Kitterman JA, Phibbs RH, et al. Treatment of the idiopathic respiratorydistress syndrome with continuous positive airway pressure. N Eng/ J Med Overseas Ed 1971;284:1333-40.

3 Sweet DG, Carnielli V, Greisen G, et al. European Consensus Guidelines on the Management of Respiratory Distress Syndrome - 2019 Update. Neonatology 2019:115:432-50.

4 Jasani B, Ismail A, Rao S, et al. Effectiveness and safety of nasal mask versus binasal prongs for providing continuous positive airway pressure in preterm infants-a systematic review and meta-analysis. Pediatr Pulmonol 2018;53:987-92.

5 King BC, Gandhi BB, Jackson A, et al. Mask versus prongs for nasal continuous positive airway pressure in preterm infants: a systematic review and meta-analysis. Neonatology 2019:116:100-14.

6 Razak A, Patel W. Nasal mask vs binasal prongs for nasal continuous positive airway pressure in preterm infants: a systematic review and meta-analysis. Pediatr Pulmonol 2020;55:2261-71.

7 Kieran EA, Twomey AR, Molloy EJ, et al. Randomized trial of prongs or mask for nasal continuous positive airway pressure in preterm infants. Pediatrics 2012;130:e1170-6.

8 Poets CF, Lim K, Marshall A, et al. Mask versus nasal prong leak and intermittent hypoxia during continuous positive airway pressure in very preterm infants. Arch Dis Child Fetal Neonatal Ed 2021;106:81-3.

9 Bashir T, Murki S, Kiran S, et al. 'Nasal mask' in comparison with 'nasal prongs' or 'rotation of nasal mask with nasal prongs' reduce the incidence of nasal injury in preterm neonates supported on nasal continuous positive airway pressure (nCPAP): a randomized controlled trial. PLoS One 2019;14:e0211476.

10 De Paoli AG, Morley CJ, Davis PG, et al. In vitro comparison of nasal continuous positive airway pressure devices for neonates. Arch Dis Child Fetal Neonatal Ed 2002;87:42F-5.

11 Green EA, Dawson JA, Davis PG, et al. Assessment of resistance of nasal continuous positive airway pressure interfaces. Arch Dis Child Fetal Neonatal Ed 2019;104:F535-9.

12 Davis PG, Morley CJ, Owen LS. Non-invasive respiratory support of preterm neonates with respiratory distress: continuous positive airway pressure and nasal intermittent positive pressure ventilation. Semin Fetal Neonatal Med 2009;14:14-20.

13 Frey U, Stocks J, Coates A, et al. Specifications for equipment used for infant pulmonary function testing. ERS/ATS Task Force on standards for infant respiratory function testing. European Respiratory Society/American Thoracic Society. Eur Respir J 2000;16:731-40.

14 Schmalisch G, Fischer H, Roehr CC, et al. Comparison of different techniques to measure air leaks during CPAP treatment in neonates. Med Eng Phys 2009;31:124-30

15 Rigatto H, Brady JP. A new nosepiece for measuring ventilation in preterm infants. J Appl Physiol 1972;32:423-4.

16 Donaldsson S, Falk M, Jonsson B, et al. Imposed work of breathing for flow meters with in-line versus flow-through technique during simulated neonatal breathing. PLoS One 2015:10:e0133432.

17 Hückstädt T, Foitzik B, Wauer RR, et al. Comparison of two different CPAP systems by tidal breathing parameters. Intensive Care Med 2003;29:1134-40.

18 Fischer HS, Roehr CC, Proquitté H, et al. Influence of nose and mouth leaks on peripheral oxygen saturation during continuous positive airway pressure in neonates. World J Pediatr 2013:9:318-22.

19 Moss ML. The veloepiglottic sphincter and obligate. Nose breathing in the neonate. J Pediatr 1965;67:330-1.

20 Rodenstein DO, Kahn A, Blum D, et al. Nasal occlusion during sleep in normal and near-miss for sudden death syndrome infants. Bull Eur Physiopathol Respir 1987;23:223-6.

21 Bergeson PS, Shaw JC. Are infants really obligatory nasal breathers? Clin Pediatr 2001:40:567-9. 